\title{
Some Biological Aspects of Fish Species Arius jella (Day, 1877) Occurring in the Negombo Estuary
}

\author{
Ekanayake N.D. and De Alwis S.M.D.A.U.* \\ Department of Zoology, University of Sri Jayewardenepura, Sri Lanka \\ *uthpala.dealwis@yahoo.com
}

\begin{abstract}
Degradation of the water quality of Negombo estuarine system due to pollution from different sources has significantly altered the species composition of fish and Arius jella (English: Blackfin sea cat fish, Sinhala: Anguluwa) which is associated with degraded water conditions has become the most prominent fish species. Present study was carried out to study some biological aspects of these species. Samples for the study were collected from Outrigger Canoe fish catches from February to December 2015, by monthly field visits. On each sampling day, $50-60 \%$ of operated Outrigger Canoes were sampled to get necessary data of A. jella. Standard length ranged between $10.0-33.0 \mathrm{~cm}$ and the relative growth condition of the fish population was allometrically negative with " $b$ " value $<3.0$. The ratio of males to females in the population during the study period was 0.9:1.0 (X2=0.1320). Highest GSI value of female fish was shown in May and lowest GSI value was shown in September. Average fecundity of mature ovary ranged from 30-42 eggs. Mean egg diameters of stage I eggs, stage II, stage III eggs varies $0.62 \pm 0.19,6.64 \pm 0.53$ and $12.11 \pm 1.18$ respectively. Parental care was observed and eggs were found in the mouths of male fish in the months of March, May, and July. These observations are important as baseline information to assess the water quality of the estuary which will be reflected through the changes of biological aspects of this pollution indicator species.
\end{abstract}

Keywords: Negombo estuary, Fishery, Fish, Crustacean, Reproductive biology, Arius jella 